\title{
Epidemiologia e aspectos imunopatológicos do vírus da imunodeficiência humana (HIV): revisão de literatura
}

\section{Epidemiology and immunopathology of human immunodeficiency virus (HIV): literature review}

\author{
Bruna de Oliveira de Melo한 Lilya Xelle de Brito Rodrigues ${ }^{2}$; Joveliane de Melo Monteiro ${ }^{3}$; \\ Mariana Oliveira Arruda ${ }^{4}$; Maria Rosa Quaresma Bomfim ${ }^{5}$
}

RESUMO: O vírus da imunodeficiência humana (HIV) infecta as células do sistema imunológico do indivíduo provocando uma queda progressiva nos linfócitos $\mathrm{T}$ CD4+, debilitando progressivamente o sistema imune e deixando-o mais vulnerável a diversas infecções por patógenos oportunistas e ao surgimento de cânceres de etiologia rara. Este estudo de revisão tem como objetivos explorar os dados epidemiológicos e os aspectos imunopatológicos das infecções pelo HIV-1. As buscas de artigos relacionados ao tema foram feitas nos bancos de dados PubMed; Latin American \& Caribbean Health Sciences Literature (LILACS); Scientific Electronic Library Online (SciELO); Science Direct; CAPES (Journal Portal databases) e BIREME (Biblioteca Virtual em Saúde). Os resultados demonstraram que as infecções pelo HIV-1 continuam sendo um grave problema de saúde pública mundial, com as maiores taxas de infecção em países do continente africano e outros países com condições socioeconômicas semelhantes. No Brasil, está ocorrendo um aumento no número de infectados na faixa etária de 50 anos ou mais, com um leve declínio na taxa de infectados nas demais faixas etárias. As principais formas de transmissão do HIV são por relação sexual desprotegida, transfusão de sangue e hemoderivados, compartilhamento de agulhas entre usuários de drogas injetáveis, de mãe para filho durante a gestação, parto e aleitamento materno e, acidentalmente, no ambiente de trabalho, entre profissionais da saúde. A síndrome da imunodeficiência adquirida - AIDS é considerada a última fase da infecção pelo HIV. Entretanto, nos últimos anos, tem sido observado um leve declínio nas taxas de infecção pelo HIV-1, que provavelmente está associada ao sucesso obtido pela terapia com antirretrovirais - drogas que controlam as taxas de replicação do vírus. Contudo, tem sido registrada a ocorrência de resistência clínica aos fármacos que compõem o coquetel de tratamento. Neste sentido, mais estudos são necessários para se ampliar o conhecimento sobre a dinâmica do vírus durante a infecção e interação com as células de defesa humana, a fim de minimizar os efeitos imunopatológicos, bem como para se descobrir potenciais alvos para o desenvolvimento de uma vacina segura e eficaz.

PALAVRAS-CHAVE: HIV. AIDS. Epidemiologia. Imunopatologia. Aspectos imunopatológicos do HIV.

\footnotetext{
${ }^{1}$ Acadêmica do $7^{\circ}$ período do curso de Biomedicina da Universidade CEUMA - São Luís, aluna de iniciação científica PIBIC. Bolsista da FAPEMA.E-mail: brunaoliv.96@gmail.com

${ }^{2}$ Acadêmica do $7^{\circ}$ período do curso de Biomedicina da Universidade CEUMA - São Luís, aluna de iniciação científica PIBIC.

E-mail:lilyarodrigues@ hotmail.com

${ }^{3}$ Graduanda no curso de Biomedicina na Universidade Ceuma, $7^{\circ}$ período do curso de Biomedicina e aluna de Iniciação Cientifica no Laboratório de Microbiologia Clinica, bolsista da FAPEMA. E-mail:jovelianemello53@gmail.com

${ }^{4}$ Graduada em Ciências Biológicas pela Universidade Federal do Maranhão (2009), mestrado em Microbiologia Médica pela Universidade Federal do Ceará (2011). Doutorado em Biotecnologia pela Universidade Federal do Amazonas/Universidade Federal do Maranhão (2016). Possui experiência na área de Microbiologia, com ênfase em Microbiologia Médica, atuando principalmente com viroses respiratórias e bioprospecção de produtos naturais. E-mail: mariana_o.arruda@yahoo.com.br

${ }^{5}$ Professora Orientadora. Graduada em Odontologia pela Pontifícia Universidade Católica de Minas Gerais. Mestrado, Doutorado e Pós-Doutorado em Ciências Biológicas pela Universidade Federal de Minas Gerais, área de concentração Microbiologia. Docente do programa de Doutorado em Biotecnologia e Biodiversidade da Rede BIONORTE. Professora do Programa de Pós-graduação Mestrado em Biologia Parasitária da Universidade do CEUMA-São Luís-MA. E-mail: mrqbomfim@gmail.com
} 


\begin{abstract}
Human immunodeficiency virus (HIV) infects the cells of the individual immune system causing a progressive decrease in CD4 $+\mathrm{T}$ lymphocytes, progressively weakening the immune system and making it more vulnerable to various infections by opportunistic pathogens and to the appearance of rare cancers. This review study aims to explore the epidemiological data and immunopathological aspects of HIV-1 infections. The search for articles related to the theme were performed in the databases PubMed; Latin American \& Caribbean Health Sciences Literature (LILACS); Scientific Electronic Library Online (SciELO); Science Direct; CAPES (Journal Portal databases) and BIREME (Virtual Health Library). The results showed that the HIV infection remains a serious public health problem worldwide, with the highest rates of infection in countries on the African continent and other countries with similar socioeconomic conditions. In Brazil is an increase in the number of infected persons in the age group of 50 years or more, despite a slight decline in the rate of infected in the other age ranges. The main forms of HIV-1 transmission are through unprotected sexual intercourse, blood transfusion and blood products, needle sharing among injecting drug users, from mother to child during pregnancy, childbirth and breastfeeding, and accidentally in the work environment among healthcare professionals. The acquired immunodeficiency syndrome -AIDS is considered as the last stage of HIV-1 infection. However, in recent years, there has been noted a slight decline in rates of HIV-1 infection, that is probably associated with the success obtained by treatment with antiretroviral therapy, drugs that control the rates of virus replication. However, it has been recorded the occurrence of clinical resistance to drugs that compose the cocktail of treatment. In this sense, more studies are needed to expand the knowledge about the dynamics of the virus during infection and interaction with cells of human defense, in order to minimise the adverse immunopathological, as well as to discover potential targets for the development of a safe and effective vaccine.
\end{abstract}

KEYWORDS: HIV. AIDS. Epidemiology. Immunopathology. Immunopathological aspects of HIV.

\title{
1 Introdução
}

A síndrome da imunodeficiência adquirida (AIDS) é uma doença causada pelo vírus da imunodeficiência humana (HIV). Este vírus pertence à família Retroviridae, subfamília. Orthoretrovirinae, gênero Lentivirus (Comitê Internacional de Taxonomia Viral (ICTV, 2009). O material genético do HIV é constituído por duas moléculas de ácido ribonucleico (RNA) de fita simples, que são protegidas por um capsídeo glicoproteico (ICTV, 2009).

Morfologicamente, a partícula do HIV em sua forma "madura" apresenta-se esférico, medindo entre 100 a 120 nanômetros de diâmetro. E, com base em suas características genéticas e diferenças nos antígenos de superfície, este vírus é classificado em dois tipos: HIV-1 e HIV-2 (ICTV, 2009). O HIV-1 tem distribuição mundial, enquanto que o HIV-2 é mais frequentemente detectado em indivíduos de países do continente africano (SHARP; HAHN, 2011). Devido a essa característica de distribuição geográfica, no presente estudo, será enfocado apenas o HIV-1. 
O HIV-1 causa uma infecção crônica em seres humanos que é caracterizada por alta viremia plasmática, perda progressiva de linfócitos T CD4 + e imunodeficiência severa, resultando no estabelecimento de infecções oportunistas e da AIDS (MWIMANZI et al., 2012). Este vírus apresenta alta taxa de mutações durante o processo de replicação, no interior das células de defesa do indivíduo, e tem como alvo principal os linfócitos T-CD4 +, provocando gradativamente a destruição dessas células (MWIMANZI et al., 2012; OKOYE; PICKER, 2013). Como consequência da depleção desses linfócitos, ocorre uma imunossupressão progressiva e o indivíduo fica mais suscetível a diversas comorbidades e infecções oportunistas (OKOYE; PICKER, 2013; CACERES et al., 2015).

As principais formas de transmissão do HIV são através das relações sexuais desprotegidas, de mãe para filho (s), transfusões de sangue e de hemoderivados, e pelo contato com material perfurocortante contaminado (SHAW; HUNTER, 2012, GERMAN ADVISORY COMMITTEE BLOOD, 2016). Apesar das diferentes vias de transmissão do HIV, a principal continua sendo através de relações sexuais desprotegidas, proporcionando o surgimento de epidemias em nível mundial (FARIA et al., 2014).

Alguns fatores aumentam o risco de transmissão do HIV durante as relações sexuais, entre os quais a presença de alta viremia, período menstrual e presença de outras doenças sexualmente transmissíveis como, por exemplo, cancro mole, sífilis e herpes genital (MINISTÉRIO DA SAÚDE, 2006).

Segundo o Programa Conjunto das Nações Unidas sobre HIV/AIDS (UNAIDS), o número de casos de infecção pelo HIV tem crescido assustadoramente em todo o mundo. Em 2016, um total de 36.7 milhões de pessoas eram portadoras do HIV, deste total 20.9 milhões estavam em tratamento com fármacos antirretrovirais (UNAIDS, 2016; 2017). Entre as populações consideradas de alto risco epidemiológico para a ocorrência de infecção pelo HIV, destacam-se os clientes de profissionais do sexo, com uma taxa global de 18\%, seguidos pelos homossexuais representando $12 \%$, usuários de drogas injetáveis, com $8 \%$ dos casos, e profissionais do sexo, com $5 \%$ dos infectados (UNAIDS, 2017).

No Brasil, os casos de infecção pelo HIV começaram a ser diagnosticados desde o final de 1980, e até junho de 2017, foram notificados no país 882.810 casos, com uma média de 40 mil novos casos nos últimos cinco anos. Apesar desses números expressivos, no período de 2006 até 2016, houve uma queda de 5,1\%. Em 2006, a taxa foi de 19,9 casos/100 mil habitantes e, em 2016, 
de 18,5/100 mil habitantes (MINISTÉRIO DA SAÚDE, 2017). O tratamento com o coquetel de fármacos antirretrovirais tem sido responsável por esse declínio significativo, em torno de $48 \%$, no número de óbitos por AIDS no país. A queda do número de mortes tem ocorrido principalmente entre as mulheres infectadas, quando comparada aos homens. Entretanto, as mulheres que vieram a óbito por causa da AIDS, estavam em plena idade reprodutiva, entre 15 e 39 anos de idade (UNAIDS, 2017).

Estes dados epidemiológicos são extremamente importantes, uma vez que, apesar do enorme progresso científico alcançado nos últimos 30 anos na área médica, a AIDS ainda é considerada uma das doenças infectocontagiosas mais devastadoras para a humanidade, uma vez que não há vacinas, não tem cura, o tratamento é caro e por toda a vida do infectado (OKOYE; PICKER, 2013; UNAIDS, 2017). Neste contexto, é necessário aprimorar o conhecimento sobre a dinâmica do vírus, a sua interação com o hospedeiro, bem como os seus efeitos devastadores sobre o organismo do infectado, para que, desta forma, seja possível encontrar meios de oferecer ao doente uma melhor qualidade de vida.

\section{Material e Métodos}

Estudo de revisão da literatura sobre os aspectos epidemiológicos e imunopatológicos do HIV em artigos publicados em Inglês, Espanhol e Português. Para a busca de artigos científicos sobre este tema, foram feitas buscas em bancos de dados do PubMed; Latin American \& Caribbean Health Sciences Literature (LILACS); Scientific Electronic Library Online (SciELO); Science Direct; CAPES (Journal Portal databases) e BIREME (Biblioteca Virtual em Saúde) -, com a utilização das palavras-chave: Vírus da imunodeficiência humana; HIV; Síndrome da Imunodeficiência Adquirida, AIDS, Epidemiologia do HIV; Imunopatologia do HIV; aspectos imunopatológicos do HIV -, nos três idiomas citados.

Os critérios de inclusão foram artigos científicos que abordaram o tema e que abrangeram ambos gêneros de indivíduos acometidos pelo HIV, em todas as faixas etárias. Como critério de exclusão, não foram selecionados artigos publicados em outras línguas, os que abordaram o HIV tipo 2, e descrição de casos clínicos. 


\section{Resultados e Discussão}

\subsection{Aspectos epidemiológicos do HIV}

Pesquisas sobre a origem do HIV sugerem que a primeira infecção em humano ocorreu em Kinshasa, (atual República Democrática do Congo), em torno de 1920, quando o HIV foi transmitido de primatas chimpanzés para humanos. Até a década de 1980, não havia uma epidemiologia sobre o número de pessoas que foram infectadas com o HIV ou que desenvolveram a AIDS. A doença e seu agente causal eram, até então, desconhecidos, uma vez que não haviam sido acompanhados a sua transmissão e nem os sinais ou sintomas visíveis (FARIAS et al., 2014; AVERT, 2017).

O primeiro caso de AIDS descrito ocorreu no Zaire (atual República Democrática do Congo), na África, no início do ano de 1980, num homem heterossexual, sendo denominada de "slim disease" porque era acompanhada de diarreia e perda de peso. Desde então, o HIV-1 foi disseminado para os habitantes de outras regiões do continente africano, sendo transmitido entre as pessoas heterossexuais, através do sexo desprotegido (SHAO; WILLIAMSON, 2012).

É importante ressaltar que o continente africano é constituído por 54 países e, em todos eles, a prevalência de infecção pelo HIV é extremamente alta, variando de 0,1 a 22,2\% da população da faixa etária entre 15 e 49 anos de idade. A maior prevalência foi verificada em Botswana, na África do Sul. Assim, desde o surgimento dos primeiros casos de infecção pelo HIV, os países africanos são os que apresentam o maior número de casos (ROSER, 2017).

Atualmente, $68 \%$ de todos os casos de infectados pelo HIV/AIDS no mundo ainda se encontram na África, sendo que diferentes fatores socioeconômicos, sócio-demográficos e comportamentais contribuem para a permanência dessa alta prevalência, entre os quais se destacam: a alta carga viral nos infectados em decorrência da falta de tratamento; a pobreza; a condição da dependência feminina em relação aos seus maridos e companheiros, a baixa adesão ao uso de preservativos, altas taxas de coinfecções com malária, tuberculose e outras doenças tropicais e início precoce das atividades sexuais, entre outros (SAI et al., 2016; ROSER, 2017).

Do continente africano o HIV foi disseminado via heterossexual para o continente asiático, alcançando a Tailândia, Índia e China. A partir daí a epidemia de HIV se espalhou, via heterossexual e homossexual, e alcançou as Américas Central, do Norte e do Sul (SHAO; WILLIAMSON, 2012). 
Em setembro de 1981, nos Estados Unidos, ocorreram os primeiros relatos da síndrome da imunodeficiência adquirida, conhecida como AIDS. Os enfermos eram acometidos por uma pneumonia grave causada pelo fungo Pneumocystis carinii, ou apresentavam um raro tumor maligno, o sarcoma Kaposi, seguidos de um grande comprometimento do sistema imunológico. Os pacientes infectados pelo HIV eram principalmente do sexo masculino, homossexuais, ou usuários de drogas injetáveis (BRASIL, 2012; OKOYE; PICKER, 2013).

No Brasil, o primeiro caso de AIDS foi notificado em 1980, em São Paulo. No final dos anos oitenta, casos de AIDS foram detectados em várias regiões do país, principalmente nas grandes metrópoles, como Rio de Janeiro e São Paulo (MINISTÉRIO DA SAÚDE, 2006). A partir de 1980 até junho de 2017, foram registrados 576.245 (65,3\%) casos de AIDS em homens e 306.444 (34,7\%) em mulheres (MINISTÉRIO DA SAÚDE, 2017). Deste total, a maior concentração de notificações ocorreu nas regiões Sudeste e Sul, correspondendo cada qual a 52,3\% e 20,1\% do total de casos; as regiões Nordeste, Norte e Centro-Oeste corresponderam a 15,4\%, 6,1\% e 6,0\% do total dos casos, respectivamente (MINISTÉRIO DA SAÚDE, 2017).

Com relação à faixa etária dos acometidos pela AIDS no Brasil, a maior concentração de caso tem ocorrido entre indivíduos com idade entre 25 e 39 anos, em ambos os sexos. Os casos nessa faixa etária correspondem a 52,9\% no sexo masculino e a 49,0\% no sexo feminino, do total registrado de 1980 a junho de 2017 (MINISTÉRIO DA SAÚDE, 2017).

Nesse contexto, a infecção pelo vírus da imunodeficiência humana (HIV) enseja uma epidemia que representa um fato global, ativo e inconstante, pois a forma do evento em diferentes regiões do mundo dependerá da conduta de cada pessoa e de toda sociedade (MONDAL; SHITAN, 2013).

\subsection{Aspectos imunopatológicos das infecções pelo HIV}

O estabelecimento da infecção pelo HIV-1 ocorre logo após o contato do vírus com as células do indivíduo no local de entrada, que acontece em grande parte através das mucosas (vaginal, peniana, anal ou oral), que pode receber as partículas virais veiculadas pelo sêmen, fluidos vaginais, sangue, líquidos do parto e do leite materno. Embora o HIV possa estar presente em baixas quantidades nas lágrimas, na urina e saliva, a sua transmissão através destes fluidos corporais é extremamente rara (CACHAY, 2017). 
A partir das células infectadas no local de entrada, o HIV inicia o seu ciclo replicativo e a infecção estende-se para outras células como macrófagos, células dendríticas, astrócitos, e principalmente para os linfócitos T CD4 + (LTCD4+), que são as principais células de defesa do indivíduo. As infecções pelo HIV apresentam três fases distintas: a infecção aguda, a crônica e a AIDS, que é resultante da destruição gradativa dos linfócitos TCD4+ (CACHAY, 2017).

O curso da fase aguda geralmente se desenvolve entre duas a quatro semanas após a infecção. Durante este período, a replicação do HIV ocorre aceleradamente e o indivíduo poderá sentir sintomas semelhantes ao de uma gripe, como febre, cefaleia, fadiga intensa, enfartamento ganglionar e até erupções cutâneas (CACHAY, 2017). Nas primeiras semanas da infecção, ocorre o aparecimento de anticorpos anti-HIV, que é a chamada soro conversão, período no qual a pessoa infectada possui uma titulação de vírus altíssima e viremia plasmática, facilitando consideravelmente a sua transmissão (MINISTÉRIO DA SAÚDE, 2013). Nessa fase, a imunidade inata atua liberando os LTCD4+ para tentar suprimir a infecção, mas estas células acabam tornando-se alvo do vírus. Inicia-se, então, a queda no número total destes linfócitos, bem como a perda de suas funções, devido ao efeito citotóxico durante o processo de replicação do HIV (CACHAY, 2017).

Na fase crônica da infecção, também conhecida como período de latência clínica, o HIV replica-se lentamente, e o indivíduo infectado poderá ser assintomático, mesmo sem tratamento. Ocasionalmente, sintomas leves poderão aparecer, entre os quais a diarreia, fadiga, anemia e a perda de peso progressiva e, nesta fase, o vírus pode ser transmitido normalmente para outra pessoa. Se o infectado não for submetido a tratamento com os fármacos antirretrovirais (conhecido como coquetel), no máximo em 12 anos, ocorrerá a evolução para a AIDS (MINISTÉRIO DA SAÚDE, 2013; CACHAY, 2017).

A AIDS é estágio mais grave da infecção pelo HIV e geralmente ocorre de 10 a 12 anos após a infecção primária. A imunodeficiência, que é bem característica na AIDS, é resultante da desregulação e da falha dos mecanismos homeotásticos e da imunidade celular do hospedeiro (OKOYE; PICKER, 2014).

Muito raramente, em algumas pessoas, a AIDS é o primeiro sintoma da infecção (CACHAY, 2017), e pode ser diagnosticada pela presença de uma ou mais infecções oportunistas como o câncer, ou aquelas causadas por fungos, bactérias e vírus (CACHAY, 2017). A gravidade dessas infecções é dependente do órgão afetado pelo agente oportunista, entre os quais os pulmões, 
trato digestivo, rins, órgãos genitais, coração e cérebro. Geralmente, o óbito ocorre em decorrência dos efeitos cumulativos ou associados dessas infecções, ou por cânceres, como o sarcoma de Kaposi e linfoma não-Hodgkin (CACHAY, 2017).

O prognóstico das infecções pelo HIV /AIDS dependerá de alguns fatores, entre os quais: o monitoramento da quantidade de LTCD4+; a contagem de hemoglobina; a quantificação da carga viral; avaliação do estágio ou tipo de progressão da doença; presença de doenças associadas ou de infecções oportunistas; a perda de massa corporal; verificação da variação genética da molécula do antígeno leucocitário (HLA) da classe I; da faixa etária e sexo do paciente; da presença de hipersensibilidade tardia, e do monitoramento de presença de resistência aos medicamentos (conforme descritos abaixo). Todos esses parâmetros devem ser acompanhados, antes e durante o tratamento, por toda a vida do paciente (LANGFORD et al., 2007; MWIMANZI et al., 2012; SHAO; WILLIAMSON, 2012).

Com relação à quantidade de LTCD4+, é importante ressaltar que, em pessoas saudáveis, a taxa varia de 500 a 1.000 células por microlitro de sangue. No indivíduo com HIV, o número desses linfócitos é reduzido durante os primeiros meses de infecção. Após cerca de 3 a 6 meses, a contagem dos linfócitos se estabiliza, mas se não houver tratamento, a taxa geralmente continua diminuindo. Se a contagem de LTCD4+ cair abaixo de cerca de 200 células por microlitro de sangue, o sistema imunológico fica comprometido para combater infecções oportunistas e inibir o desenvolvimento de tumores malignos (LANGFORD et al., 2007; AVERT, 2017).

Os pacientes com AIDS comumente apresentam anemia numa prevalência estimada entre 63\% a 95\% (DAMINELLI et al., 2010). Apesar dos benefícios associados ao uso da terapia antirretroviral, geralmente ela pode acarretar efeitos adversos, entre os quais a supressão da medula óssea e/ou anemia hemolítica (DAMINELLI et al., 2010).

A quantificação da carga viral mostra se a replicação está ocorrendo rapidamente, lenta ou constante. Na fase aguda da infecção, a carga viral é alta e representa que o vírus está em fase replicativa. A avaliação do estágio ou tipo de progressão da doença é importante para se detectar os riscos da imunodeficiência, estabelecimento de infecções oportunistas, resistência aos fármacos do coquetel e determinar o tipo de terapia antirretroviral (GERMAN ADVISORY COMMITTEE BLOOD, 2016). A determinação da carga viral pode ser feita por métodos moleculares, como a amplificação pela reação de transcrição reversa seguida da reação em cadeia da polimerase (RTPCR). Este método tem sido utilizado para o monitoramento da infecção e auxiliar na tomada de 
decisão a respeito da intervenção clínica mais adequada nos pacientes com HIV /AIDS (CACHAY, 2017).

Com relação ao surgimento de doenças associadas em pacientes com infecções crônicas pelo HIV-1 e em tratamento contínuo com antirretrovirais eles correm o risco de desenvolverem uma série de eventos graves não relacionadas à AIDS, incluindo doenças cardiovasculares, câncer, doenças renais, doenças hepáticas, osteopenia/ osteoporose e doença neurocognitiva. Além dessas doenças, eles estão mais suscetíveis a contrair infecções oportunistas por bactérias, fungos e vírus (LANGFORD et al., 2007; DEEKS et al., 2013; AVERT, 2017).

O monitoramento da massa corporal em portadores do HIV /AIDS é um importante marcador prognóstico e deve ser feito periodicamente, uma vez que a infecção ou a doença causam distúrbios gastrointestinais que dificultam a absorção dos nutrientes. Essa desregulação metabólica provoca a perda na massa corporal magra, atribuível a qualquer causa, incluindo uma combinação de aumento do gasto de energia no repouso, redução da ingestão de calorias e má absorção gastrointestinal. A perda de peso extrema, ou caquexia, é um prognóstico ruim para pacientes com HIV /AIDS, tornando-os mais suscetíveis a infecções oportunistas e ao óbito (BROWN, 2017).

Os genes que codificam para o HLA são altamente polimórficos possuindo assim inúmeros variantes com mínimas diferenças entre si. Contudo, apesar da grande diversidade alguns loci podem ser únicos ou específicos. Este antígeno específico exerce uma forte pressão seletiva sobre o vírus influenciando a evolução da infecção viral. Entretanto, o HIV-1 desenvolve mutações específicas no seu genoma que o permite escapar da ação do HLA classe I do hospedeiro (CARLSON et al., 2015).

Com relação a influência da faixa etária dos pacientes, segundo a Organização Mundial da Saúde (WHO, 2014), as taxas de prevalência podem variar conforme a região geográfica, condições socioeconômicas, fatores comportamentais, costumes culturais e religiosos, entre outros. No continente africano tem sido verificada uma maior prevalência casos de HIV /AIDS em mulheres mais jovens, e tem se tornado uma das principais causas de morte entre estas mulheres na faixa etária entre 15-24 anos de idade (WHO, 2014). Por outro lado, no Brasil, a faixa etária mais afetada tanto de homens quanto de mulheres é de 20 a 39 anos de idade, não existindo uma diferença estatística significante. Entretanto, tem sido observada uma tendência de aumento em indivíduos com idade $\geq 50$ anos. Por exemplo, de 1996 a 2006, o número de infectados nesta faixa etária mais que dobrou (CARDOSO et al., 2013). 
As diferenças sexuais em pacientes portadores do HIV /AIDS devem ser consideradas ao se monitorar a evolução dos efeitos imunopatológicos em portadores do HIV /AIDS. As diferenças dos mecanismos biológicos incluem a modulação de vias imunológicas por hormônios sexuais e efeitos de dosagem de genes imunomoduladores codificados pelo cromossomo $\mathrm{X}$ feminino. Durante as infecções primária por HIV-1, as mulheres mostram níveis de carga viral mais baixos, entretanto na fase crônica a progressão para a AIDS é mais rápida, em comparação com os homens com os mesmos níveis de carga viral. Tem sido verificado que as mulheres infectadas com HIV-1 tendem a ter níveis mais elevados de ativação do sistema imune inato e expressão de genes estimulados por interferon alfa, este fato se deve a presença de um receptor Toll-like-7 nas suas células dendríticas e plasmócitos (SEILLET et al., 2013; ZIEGLER; ALTFELD, 2016).

Quanto aos aspectos hipersensibilidade tardia, os mecanismos biológicos que desencadeiam no gênero feminino uma resposta imunológica mais vigorosa diante de algumas infecções virais e a algumas doenças autoimunes, ainda não estão complemente elucidados cientificamente, mas estudos mostraram que pode estar relacionado aos fatores de riscos ambientais, diferenças entre o microbioma feminino e o masculino (YURKOVETSKIY et al., 2013), tipo de hormônio esteroide secretado pelas gônadas ( SEILLET et al., 2013) e os efeitos diretos dos fatores ligados aos cromossomos X e Y (FISH, 2008; LIBERT, 2010; MARKLE; FISH, 2014).

O primeiro registro de resistência clínica a um agente retroviral ocorreu em 1989, quando testes demonstraram várias mutações no gene que codifica para a enzima transcriptase reversa no material genético de um isolado clínico recuperado de um paciente que fazia uso de zidovudine (AZT), desde então, variantes de HIV com o perfil de resistência foram sendo identificados a todos os agentes antirretrovirais disponíveis naquela ocasião (KOZAI, 2017).

\subsubsection{Tratamento dos pacientes com HIV /AIDS}

Avanços científicos significativos na área farmacêutica foram obtidos nos últimos 30 anos, principalmente no desenvolvimento de diferentes classes de medicamentos para o tratamento dos pacientes com HIV /AIDS. Tais fármacos têm sido utilizados com sucesso para controlar a replicação do vírus, oferecendo um aumento significativo na taxa de sobrevida e uma qualidade de vida melhor ao paciente (AVERT, 2017; CACHAY, 2017).

É importante notar que as principais drogas utilizadas no tratamento desses pacientes são inibidores das enzimas que atuam na replicação do HIV (ARTS; HAZUDA, 2012). Os fármacos que compõem o coquetel para o tratamento da AIDS são idade específicos e estão distribuídos em 
seis diferentes classes de antivirais com base em seus mecanismos moleculares de ação e perfil de resistência: (1) inibidores da transcriptase reversa análogos de nucleosídeos (2) não inibidores da transcriptase reversa não nucleosídeos, (3) inibidores da integrase, (4) inibidores de protease, (5) inibidores da fusão, e (6) antagonistas de correceptores (ARTS; HAZUDA, 2012).

Neste sentido, um ótimo regime terapêutico inicial para a maioria dos pacientes tem sido um coquetel constituído de dois tipos de inibidores da transcriptase reversa análogos de nucleosídeos associados a um inibidor da integrasse do vírus. Outro regime terapêutico efetivo que também tem sido utilizado com sucesso é composto de dois tipos de inibidores da transcriptase reversa análogos de nucleosídeos mais um inibidor da protease viral (GÜNTHARD et al., 2016; KOZAI, 2017).

O tratamento e o acompanhamento do paciente com HIV/AIDS devem ser interdisciplinares, uma vez que a condição soropositividade ou de doente pode provocar problemas psicológicos e psiquiátricos que dificultam a aceitação pelo paciente da sua própria situação e à adesão ao tratamento (LELUBRE et al., 2015). Ressalte-se que, apesar do tratamento com os antirretrovirais permitir aos pacientes com AIDS uma sobrevida maior e com melhor qualidade, não se elimina a sua condição de portador e de potencial transmissor do HIV (CACHAY, 2017).

Nesse contexto, são necessárias campanhas frequentes para reforçar e esclarecer a população em geral da necessidade da prática do sexo seguro em todos os tipos de relações sexuais, uma vez que o sucesso oferecido pelo tratamento tem provocado uma falsa impressão de cura, ocasionando, assim, certo descuido e a não utilização do preservativo.

\section{Conclusão}

Os resultados da pesquisa mostraram que o HIV está mundialmente disseminado, variando apenas as taxas de prevalência entre os países, sendo que a epidemiologia das infecções está relacionada a diferentes fatores, entre os quais: gênero, faixa etária, via de transmissão, não adesão ao tratamento ou falta de acesso a este, todos associados às altas taxas de mortalidade entre os grupos populacionais infectados.

Os países com as maiores taxas de prevalência do HIV estão localizados no continente africano, nos quais as mulheres jovens são as mais afetadas. No Brasil, está ocorrendo um aumento no número de infectados na faixa etária de 50 anos ou mais, apesar de uma queda da taxa de infectados nas demais faixas etárias.

A ativação crônica do sistema imunológico do paciente é uma característica da progressão da infecção pelo HIV, resultando na deterioração das células LTCD4+ e causando uma 
imunodeficiência grave (AIDS), que é responsável pelo estabelecimento de infecções oportunistas, surgimento de cânceres e óbito.

A utilização do coquetel de antirretrovirais no tratamento dos infectados, ainda assintomáticos ou com AIDS, tem diminuído as taxas de óbitos e aumentado a longevidade dos pacientes. Entretanto, o tratamento não elimina a condição de portador e de potencial transmissor do HIV.

Devido às características genéticas do HIV, tem ocorrido linhagens virais com mutações, causando o fenômeno da resistência clínica aos antirretrovirais e dificultando a cura do paciente.

A somatória dos resultados mostrou que mais estudos são necessários para se ampliar o conhecimento sobre a dinâmica do vírus durante a infecção e interação com as células de defesa do hospedeiro, a fim de minimizar os efeitos imunopatológicos, bem como se descobrir potenciais alvos para o desenvolvimento de uma vacina segura e eficaz.

\section{Referências}

ARTS, E. J.; HAZUDA, D. J. "HIV-1 Antiretroviral Drug Therapy." Cold Spring Harbor. Perspectives in medicine, v.2.4 (2012), n. a007161. PMC. Web. 28 Dec. 2017.

AVERT. Global information and education on HIV and AIDS. History of HIV and AIDS overview. Disponível em: < https://www.avert.org/professionals/history-hiv-aids/overview >. Acessado em 27 dezembro 2017.

BRASIL. Secretaria de vigilância em saúde. Relatório de Progresso da Resposta Brasileira ao HIV/AIDS (2010-2011), Brasília, 2012. Disponível em: $<$ http://www.aids.gov.br/sites/default/files/anexos/publicacao/2012/51906/ungass_2012_portugues_ rev_08jun_pdf_51895.pdf>. Acessado em 28 setembro de 2017.

BROWN, T. HIV-Associated Weight Loss and Wasting: Addressing an Ongoing Burden. Medscape CME / ABIM MOC. Disponível em: <https://www.medscape.org/viewarticle/876725_2>. Acessado em 29 dezembro 2017.

CACERES, N. A.; VIEIRA, M. M. C.; VIEIRA, I. F.; MONTELEONE, V. F.; NETO, L. J. M.; BONAFE, S. Opportunistic Infections in Aids Patients. Archives of medicine, v. 7, n. 5:10, p.1-17. 2015.

CACHAY, E. R. Human Immunodeficiency Virus (HIV) Infection. Infections - Merck Manuals Consumer version. 2017. Disponívelem: $<$ https://www.merckmanuals.com/home/infections/humanimmunodeficiency-virus-hiv-infection/human-immunodeficiency-virus-hiv-infection\#v27413958>. Acessado em 28 de dezembro de 2017. 
CARLSON, J. M.; ANH, Q. L. S.; ZABRINA, L. B. HIV-1 adaptation to HLA: a window into virus-host immune interactions. Trends in Microbiology. v. 23, n. 4 , p.212-224. 2015.

CARDOSO, D. S.; WAGNER, T. T.; SANTINI, O. M.; MARINS, L. M. S.; VELOSO, V. G.; GRINSZTEJN. B. Aging with HIV: a practical review. Brazilian Journal of Infectious Diseases. v. 17, n. 4, p. 464-79. 2013.

COMITÊ INTERNACIONAL DE TAXONOMIA VIRAL (ICTV). Family: Retroviridae. Chapter Version: ICTV 9th Report; 2009.Taxonomy Release Virion properties. Disponível em: < https://talk.ictvonline.org/ictv-reports/ictv_9th_report/reverse-transcribing-dna-and-rna-viruses2011/w/rt_viruses/161/retroviridae >. Acessado em 28 de dezembro de 2017.

DAMINELLI, E. N.; TRITINGER, A.; SPADA, C. Alterações hematológicas em pacientes infectados pelo vírus da imunodeficência humana submetidos à terapia antirretroviral com e sem inibidor de protease. Revista Brasileira de Hematologia e Hemoterapia. V. 32, n. 1, p. 10-15. $\underline{2010 .}$

DEEKS, S. G.; LEWIN, S. R.; HAVLIR, D. V. The End of AIDS: HIV Infection as a Chronic Disease. Lancet, v. 382, n. 9903, p. 1525-1533. 2013

FARIA, N. R.; RAMBAUT, A.; SUCHARD, M. A.; BAELE, G.; BEDFORD, T.; WARD, M. J.; LEMEY, P. The early spread and epidemic ignition of HIV-1 in human populations. Science, v. 346, n. 6205 , p. 56-61. 2014.

FISH, E.N.; The X-files in immunity: sex-based differences predispose immune responses. Nature reviews Immunology, v. 8, n. 9, p. 737-44. 2008

GERMAN ADVISORY COMMITTEE BLOOD (Arbeitskreis Blut), Subgroup "Assessment of Pathogens Transmissible by Blood." Human Immunodeficiency Virus (HIV). Transfusion medicine and Hemotherapy, v. 43, n. 3, p. 203-222. 2016.

GÜNTHARD, H. F.; SAAG, M. S.; BENSON, C. A.; DEL RIO, C.; ERON, J. J.; GALLANT, J. E.; HOY, J. F.; MUGAVERO, M. J.; SAX P. E.; THOMPSON, M. A.; GANDHI, R. T.; LANDOVITZ, R. J.; SMITH, D M.; JACOBSEN, D. M.; VOLBERDING, P. A. Antiretroviral Drugs for Treatment and Prevention of HIV Infection in Adults: Recommendations of the International Antiviral Society-USA Panel, JAMA, v. 316, n. 2, jul, p. 191-210. 2016.

KOZAI, J. M. Overview of HIV drug resistance testing assays. UpToDate. Disponível em: <https://www.uptodate.com/contents/overview-of-hiv-drug-resistance-testing-assays >. Acessado em 30 de dezembro de 2017.

LANGFORD, S. E.; ANANWORANICH, J.; COOPER, D. A. Predictors of disease progression in HIV infection: a review. AIDS. Research and Therapy, v. 4, n. 11, maio, p. 11. 2007.

LIBERT, C.; DEJAGER, L.; PINHEIRO, I.; The X chromosome in immune functions: when a chromosome makes the difference. Nature reviews Immunology, v. 10, n. 8, p. 594-604. 2010.

LELUBRE, M.; KAMAL, S.; GENRE, N.; CELIO, J.; GORGERAT, S.; HUGENTOBLER, H. D.; SCHNEIDER, M. Interdisciplinary Medication Adherence Program: The Example of a University Community Pharmacy in Switzerland. BioMed Research International, v. 2015, p. 10. 2015. 
MARKLE, J. G.; FISH, E. N. SEXX matters in immunity. Trends in immunology, v. 35, n. 3, p. 97-104. 2014.

Roser, M. 'HIV / AIDS'. Published online at OurWorldInData.org. Retrieved from: Online Resource. Disponível em : $<$ https://ourworldindata.org/hiv-aids/ $>$. Acessado em 28 de dezembro de 2017.

MINISTÉRIO DA SAÚDE. Boletim Epidemiológico AIDST; Ano III, nº 01.2006.

MINISTÉRIO DA SAÚDE, SECRETARIA DE VIGILÂNCIA EM SAÚDE DEPARTAMENTO DE DST, AIDS E HEPATITES VIRAIS, PROTOCOLO CLÍNICO E DIRETRIZES TERAPÊUTICAS PARA MANEJO DA INFECÇÃO PELO HIV EM ADULTOS, Brasília. 2013.

MINISTÉRIO DA SAÚDE - SECRETARIA DE VIGILÂNCIA EM SAÚDE - DEPARTAMENTO DE VIGILÂNCIA, Prevenção e Controle das Infecções Sexualmente Transmissíveis, do HIV/Aids e das Hepatites Virais. Brasília. 2017.

MONDAL, M.; SHITAN, M. Factors affecting the HIV/AIDS epidemic: an ecological analysis of global data. African Health Sciences, v. 13, n. 2, p. 301-310. 2013.

MWIMANZI, P.; MARKLE, T. J.; UENO, T.; BROCKMAN, M. A. Human Leukocyte Antigen (HLA) Class I Down-Regulation by Human Immunodeficiency Virus Type 1 Negative Factor (HIV-1 Nef): What Might We Learn From Natural Sequence Variants? Viruses, v. 4, n. 9, p. 17111730. 2012.

OKOYE, A. A.; PICKER, L. J. $\mathrm{CD}^{+} \mathrm{T}$ cell depletion in HIV infection: mechanisms of immunological failure. Immunological reviews, v. 254, n. 1, p.54-64. 2013.

SHARP, P. M.; HAHN, B. H. Origins of HIV and the AIDS Pandemic. Cold Spring Harbor Perspectives in Medicine, v. 1, n. 1, sep. 2011.

SHAO, Y.; WILLIAMSON, C. (2012). The HIV-1 Epidemic: Low- to Middle-Income Countries. Cold Spring Harbor. Perspectives in Medicine, v. 2, n. 3. 2012.

SHAW, G. M.; HUNTER, E. HIV Transmission. Cold Spring Harbor Perspectives in Medicine, v. 2, n. 11. 2012.

SEILLET, C.; LAFFONT, S.; TRÉMOLLIÈRES, F.; ROUQUIÉ, N.; RIBOT, C.; ARNAL, J. F.; DOUIN-ECHINARD, V.; GOURDY, P.; GUÉRY, J. C. The TLR-mediated response of plasmacytoid dendritic cells is positively regulated by estradiol in vivo through cell-intrinsic estrogen receptor alpha signaling. Blood, v. 119, n. 2, jan, p. 454-64. 2012.

SIA, D.; ONADJA, Y.; HAJIZADEH, M.; HEYMANN, S. J.; BREWER, T. F.; NANDI, A. What explains gender inequalities in HIV/AIDS prevalence in sub-Saharan Africa? Evidence from the demographic and health surveys. BMC Public Health, v. 16, n. 1, nov, p. 1136. 2016.

UNAIDS. Review of data from People Living with HIV Stigma Index surveys conducted in more than 65 countries, 2016. 
UNAIDS DATA 2017. Disponível em:<http://www.unaids.org/sites/default/files/media_asset/ 20170720_Data_book_2017_en.pdf>. Acessado em 27 dezembro de 2017.

YURKOVETSKIY, L.; BURROWS, M.; KHAN, A. A.; GRAHAM, L.; VOLCHKOV, P.; BECKER, L.; ANTONOPOULOS, D.; UMESAKI, Y.; CHERVONSKY, A. V. Gender bias in autoimmunity is influenced by microbiota. Immunity, v. 39, n. 2, aug, p. 400-12. 2013.

ZIEGLER, S.; ALTFELD, M. Sex Differences in HIV-1-mediated immunopathology. Current Opinion in HIV and AIDS, v. 11, n. 2, p. 209-215. 2016. 